\title{
Spinal accessory neuropathy in patients with chronic trapezius myofascial pain syndrome
}

\author{
Asmaa Farouk El Sayed El Sharnoby ${ }^{1}$, Hussein Al-Moghazy Sultan² and Emmanuel Kamal Aziz Saba ${ }^{2 *}$ (D)
}

\begin{abstract}
Background: Myofascial pain syndrome is a common musculoskeletal problem affecting the trapezius muscle. The aim was to assess the presence of spinal accessory neuropathy in patients with unilateral chronic trapezius myofascial pain syndrome.

Results: The study included 25 patients with unilateral chronic trapezius myofascial pain syndrome and 20 apparently healthy volunteers as the control group. There was a significantly delayed spinal accessory nerve latency on the symptomatic side in comparison to either asymptomatic side $(P=0.014)$ and control group $(P=0.001)$. Compound muscle action potential amplitude did not significantly differ between the symptomatic side versus the asymptomatic side and control group. Delayed spinal accessory nerve latency was present in seven patients (28\%) and reduced compound muscle action potential amplitude in one of them (4\%). The needle electromyography of the upper trapezius muscle revealed neuropathic motor units and incomplete interference pattern in the patient who showed reduced compound muscle action potential amplitude. Abnormal rest potentials were absent in all patients. Individually, seven patients (28\%) had electrophysiological evidence of spinal accessory neuropathy, but only one (4\%) of them had clinical evidence of spinal accessory neuropathy. Patients with abnormal electrophysiological findings had longer duration of complaint and more severe pain.

Conclusions: Spinal accessory neuropathy is common among patients with chronic trapezius myofascial pain syndrome. It could contribute to increased pain severity of myofascial pain syndrome. Electrodiagnosis is a good modality for identifying subclinical spinal accessory neuropathy.
\end{abstract}

Keywords: Myofascial pain syndrome, Myofascial trigger point, Spinal accessory nerve, Spinal accessory neuropathy, Trapezius muscle

\section{Background}

Myofascial pain syndrome (MPS) is the most common etiology of chronic regional musculoskeletal pain [1]. It is characterized by the presence of myofascial trigger points (MTrPs) within a skeletal muscle associated with muscle pain and spasm. It occurs frequently in the neck and shoulder girdle muscles [1-3]. It could result from repetitive micro-trauma and overuse injuries [3].

\footnotetext{
* Correspondence: emadaziz55@yahoo.com

2Physical Medicine, Rheumatology and Rehabilitation Department, Faculty of Medicine, Alexandria University, Alexandria, Alexandria Governorate, Egypt Full list of author information is available at the end of the article
}

Trapezius muscle is a common muscle to suffer of MPS [4, 5]. This muscle is supplied by the spinal accessory nerve (SAN) (Fig. 1). It has a role in the posture and movements of the neck and shoulder [6]. The SAN is the $11^{\text {th }}$ cranial nerve. It gives motor nerve supply to the sternocleidomastoid and trapezius muscles, as well as, deep sensory innervation for proprioceptive sensation to these muscles. This is through the contribution of the cervical plexus [7-9]. Spinal accessory neuropathy causes dull aching pain, and weakness and wasting of the sternocleidomastoid and trapezius muscles with

\section{Springer Open}

() The Author(s). 2020 Open Access This article is licensed under a Creative Commons Attribution 4.0 International License, which permits use, sharing, adaptation, distribution and reproduction in any medium or format, as long as you give appropriate credit to the original author(s) and the source, provide a link to the Creative Commons licence, and indicate if changes were made. The images or other third party material in this article are included in the article's Creative Commons licence, unless indicated otherwise in a credit line to the material. If material is not included in the article's Creative Commons licence and your intended use is not permitted by statutory regulation or exceeds the permitted use, you will need to obtain permission directly from the copyright holder. To view a copy of this licence, visit http://creativecommons.org/licenses/by/4.0/. 


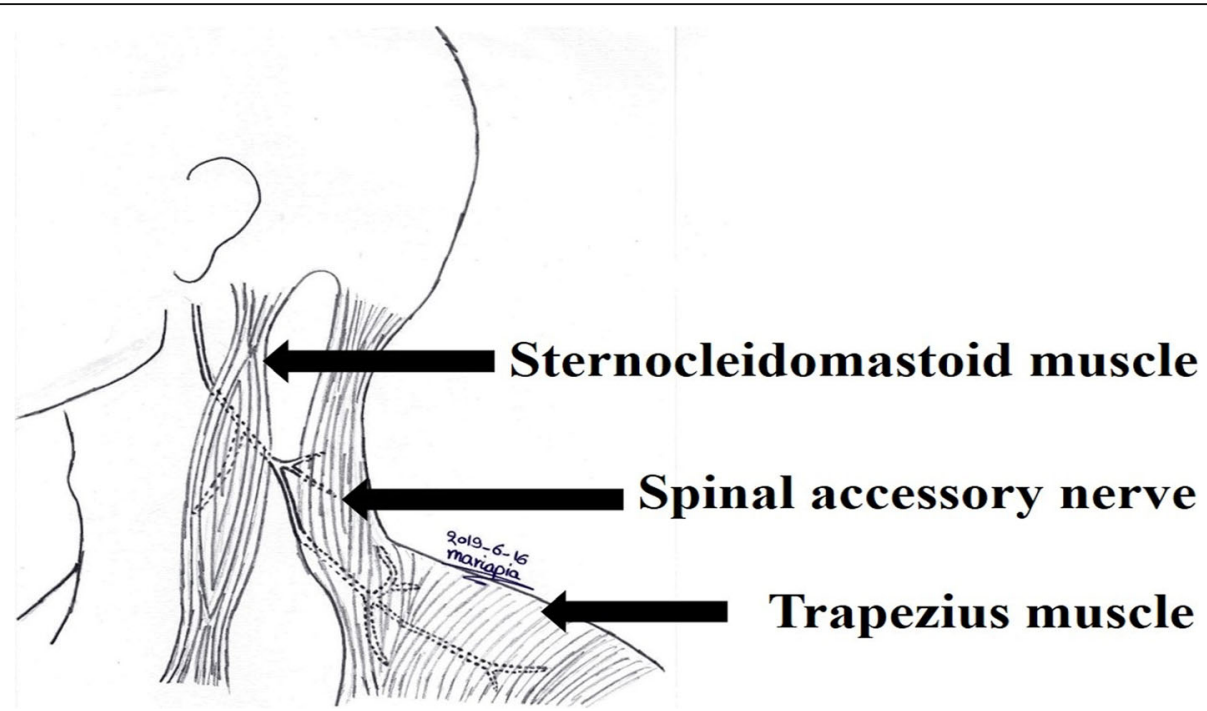

Fig. 1 The terminal part of the spinal accessory nerve and its supplied muscles (sternocleidomastoid and trapezius muscles)

winging of the scapula. In distal nerve lesions, the sternocleidomastoid muscle is not affected [10,11].

It was postulated that MPS could lead to entrapment neuropathy including spinal accessory neuropathy [12, 13]. There are scanty studies that assessed the condition of SAN in patients with chronic trapezius MPS $[14,15]$. The aim of the current study was to assess the presence of spinal accessory neuropathy in patients with unilateral chronic trapezius MPS.

\section{Methods}

This cross-sectional study included 25 patients with unilateral chronic trapezius MPS fulfilling the criteria for the diagnosis of MPS according to Travell and Simons criteria. It required the presence of five major and one minor criteria [16]. The major criteria include (i) the presence of regional pain complaint, (ii) the pain pattern follows a known distribution of muscular referred pain, (iii) the presence of palpable taut band, (iv) the presence of focal tenderness at one point or nodule within the taut band, and (v) the presence of a degree of restricted range of motion. The minor criteria include (i) manual pressure on the MTrP nodule reproduce chief pain complaint, (ii) snapping palpation of the taut band at the $\mathrm{MTrP}$ elicits a local muscle twitch response, and (iii) the pain is decreased or eliminated by muscular treatment (muscle stretching or injection of the MTrP) [16]. The patients were enrolled randomly from those attending the outpatient clinic of Physical Medicine, Rheumatology and Rehabilitation Department, Main University Hospital, Alexandria Faculty of Medicine. Exclusion criteria included patients with diabetes mellitus, other endocrine disorders, metabolic disorders, rheumatologic disorders including fibromyalgia, and neurological disorders including cervical radiculopathy, cervical myelopathy, and peripheral neuropathy. The study included 20 apparently healthy volunteers as a control group. The research was explained to the participants. Each participant gave an informed consent. Approval of the study had been provided by the local Ethics Committee of the Faculty of Medicine, Alexandria University, Egypt.

All patients were subjected to the following. Demographic data collection and history taking were done stressing on the disease duration and the predisposing risk factors for MPS. The pain severity was assessed by numerical rating scale (NRS) of pain. The patients were asked to select an integer number from 0 (no pain) to 10 (the worst pain) that best reflected the intensity of their pain [17]. Clinical examination was done stressing on musculoskeletal examination and neurological examination. The MTrPs were detected by the presence of pain when pressure was applied to the trapezius muscle over the taut bands. It was considered active MTrP if there was local tenderness associated with spontaneous pain. Latent MTrP was considered if there was localized tenderness without spontaneous pain [18]. Assessment of the muscle strength of the trapezius and sternocleidomastoid muscles was done using manual muscle testing (Medical Research Council Scale) grades [19].

Electrophysiological studies were conducted on a NIHON KOHDEN Neuropack MEB-7102 mobile unit with a two-channel evoked potential/electromyography measuring system (Nihon Kohden Corporation, Tokyo, Japan). Temperature at the skin surrounding the recording electrodes was maintained around $32-34{ }^{\circ} \mathrm{C}$ by the mean of infrared lamp [20].

The following electrophysiological parameters were applied for the motor nerve conduction study of the 
SAN: The production current ability of the bipolar stimulator was $50 \mathrm{~mA}$. The pulse duration was $0.2 \mathrm{~ms}$. The filter bandwidth was $10 \mathrm{~Hz}-10 \mathrm{kHz}$. The sweep speed was $5 \mathrm{~ms} /$ division and the sensitivity was $2-5 \mathrm{mV} /$ division. Supramaximal stimulation was ensured [21]. Spinal accessory motor nerve conduction study recording trapezius muscle was done while the participant was in the sitting position, well supported, and completely relaxed with resting of the upper limbs to relax the trapezius muscles. The active recording surface disc electrode was placed on the upper segment of the trapezius muscle at the midpoint between the acromion process of the scapula and the $7^{\text {th }}$ cervical spinous process bony prominence. The reference surface disc electrode was placed over the acromion. The bipolar stimulator was placed in the posterior cervical triangle just posterior to the midpoint of the posterior border of the sternocleidomastoid muscle, in which the cathode of the stimulator is facing distally. The ground electrode was placed between the stimulation site proximally and the recording electrodes distally [14, 22]. The latency and compound muscle action potential (CMAP) amplitude were taken for analysis. The CMAP amplitude was measured from the first negative peak to the next positive peak expressed in millivolts $(\mathrm{mV})$ [21, 22]. The SAN motor conduction study was done on the symptomatic and asymptomatic sides of all patients. However, it was done unilaterally in the control group.

Needle electromyography (EMG) of the trapezius muscle on the symptomatic side was done [23]. A concentric needle electrode was inserted in the upper part of the muscle in the midpoint of a line drawn from the $7^{\text {th }}$ cervical spinous process bony prominence to the acromion while the patient was lying on the side and the studied shoulder placed upward. Activation of the muscle was done by asking the patient to shrug the shoulder [23]. Needle EMG of the deltoid, biceps brachii, and supraspinatus muscles were done to exclude cervical radiculopathy involving fifth cervical and sixth cervical nerve roots [22]. The filter bandwidth was $50 \mathrm{~Hz}-10$ $\mathrm{kHz}$. Recording of muscle activity was done at rest (sensitivity at $50 \mu \mathrm{V} /$ division, analysis time at $100 \mathrm{~ms}$ ), minimal volition (sensitivity at $200 \mu \mathrm{V} /$ division, analysis time at $100 \mathrm{~ms}$ ) and maximal volition (sensitivity at $200 \mu \mathrm{V} /$ division, analysis time at $1 \mathrm{~s})$ [22].

Statistical analysis of data was done by using the Statistical Package of Social Science (SPSS version 17) software (Statistical Package for the Social Sciences, version 17; University of Cambridge Computing Service: London, UK; 2007). Descriptive measures (count, frequency, minimum, maximum, median, mean, and standard deviation [SD]), as well as analytic measures (MannWhitney test, Kruskal-Wallis test, chi-square test, Fisher's exact test when required, and Spearman correlation test), were used. Statistical significance was assigned to any $P$ value at $<0.05$. The reference cut-off values of the electrophysiological parameters were calculated by rounding the mean $\pm 2 \mathrm{SD}$ (obtained from the control group) to the nearest $10^{\text {th }}$ to measure the upper limit of normal or the lower limit of normal, respectively.

\section{Results}

The research included 25 patients with unilateral chronic trapezius MPS (21 females [84.0\%]). Their mean age was $37.76 \pm 13.45$ years (ranging from 19 to 64 years). The control group consisted of 20 apparently healthy volunteer (17 females [85.0\%]). Their mean age was $35.35 \pm 11.37$ years (ranging from 18 to 59 years). There were no statistically significant differences between patients and controls as regards gender $\left(X^{2}=\right.$ $0.008, P=0.629)$ and age $(Z=-0.446, P=0.656)$. Patient group included 15 housewives $(60 \%)$, six employees $(24 \%)$, one teacher $(4 \%)$, one painter $(4 \%)$, and two students $(8 \%)$.

There were 14 patients (56\%) complained of rightsided MPS and 11 patients (44\%) complained of leftsided MPS. The mean duration of complaint reported by the patients was $14.72 \pm 9.75$ months that ranged from 3 to 48 months. All patients $(100 \%)$ had predisposing risk factors for MPS in the form of overuse, and sustained and repetitive work. The mean of pain severity assessment using NRS was $7.04 \pm 1.77$ and ranged from 5 to 10. In all patients, the MPS pain increased by effort, repetitive work, and excessive loads. The pain was relieved by rest and analgesics.

Clinical examination revealed the following. Taut bands and MTrPs were detected in the trapezius muscle on the symptomatic side in all patients (100\%). However, neither taut bands nor MTrPs could be detected in other neck or shoulder girdle muscles as sternocleidomastoid, rhomboids, supraspinatus, and infraspinatus muscles. On palpation of trapezius MTrPs, pain was referred to the neck in 25 patients (100\%), dorsal back in 18 patients (72\%), shoulder in 12 patients (48\%), and proximal arm in 17 patients $(68 \%)$. There were 15 patients $(60 \%)$ that suffered from occipital headache. All patients (100\%) had one or more active MTrPs within the upper segment of the trapezius muscle. Sensation was intact over the neck, shoulder, and upper back. Motor examination of sternocleidomastoid and trapezius muscles revealed neither wasting nor weakness except one patient (4\%) who had subtle wasting of the upper fibers of trapezius muscle and weakness in the form of grade 4 manual muscle testing (Medical Research Council Scale) on examination of the trapezius muscle on the symptomatic side. There was no winging of the scapula on the symptomatic side in all patients (100\%). Subsequently, at an 
individual level, clinical evidence of spinal accessory neuropathy was found in one patient (4\%).

The results of the SAN motor conduction study are tabulated in Table 1. The SAN CMAP mean latency was significantly delayed on the symptomatic sides compared to the asymptomatic sides and control subjects, while SAN CMAP mean amplitude did not differ significantly between the symptomatic and asymptomatic sides and control group as shown in Table 1. The reference cut-off value for SAN CMAP latency was $\leq 2.7 \mathrm{~ms}$ and for SAN CMAP amplitude was $\geq 7.6 \mathrm{mV}$. Figure 2 is an illustration of the SAN CMAP obtained from an apparently healthy volunteer. Figure 3 is an illustration of the SAN CMAP obtained from the symptomatic and asymptomatic sides of a patient with spinal accessory neuropathy.

The total number of patients with abnormal SAN CMAP parameters was seven patients (28\%). In all these patients, SAN CMAP latency was delayed on the symptomatic side and there was reduced SAN CMAP amplitude in only one of them (4\%).

Abnormal EMG findings in the trapezius muscle were present in only one patient (4\%). The EMG abnormalities of this patient included the presence of neuropathic motor unit action potentials (MUAPs) (long duration, large amplitude, and polyphasic MUAPs) and incomplete interference pattern with no detected abnormal rest potentials. These abnormalities were consistent with chronic axonopathic lesion. This patient was the patient who had delayed latency and reduced amplitude of the
SAN CMAP on the symptomatic side. Normal EMG findings in the trapezius muscle were detected in the remaining 24 patients (96\%). EMG examination of the deltoid, biceps brachii, and supraspinatus muscles on the symptomatic side showed normal EMG findings in all patients (100\%). Subsequently, at an individual level, electrophysiological abnormalities consistent with spinal accessory neuropathy were detected in seven patients (28\%).

At an individual level, resulting from the clinical examination and electrophysiological assessment of the patients, there was one patient $(4 \%)$ who had clinical and electrophysiological evidence of spinal accessory neuropathy and there were six patients $(24 \%)$ who had electrophysiological evidence of subclinical spinal accessory neuropathy.

The clinical characteristics of patients with abnormal SAN motor conduction study versus those with normal SAN motor conduction study are tabulated in Table 2 . The duration of complaint was longer and pain severity assessment by NRS was higher among patients with abnormal SAN motor conduction study in comparison to those with normal SAN motor conduction study but without significant difference.

There was no statistically significant correlation between the duration of complaints with different SAN CMAP parameters on the symptomatic sides $(P>0.05)$.

The patient who had the clinical and electrophysiological evidence of spinal accessory neuropathy was a 52-

Table 1 Comparison between patient group (symptomatic and asymptomatic sides) and control group regarding different parameters of spinal accessory nerve motor conduction study

\begin{tabular}{|c|c|c|c|c|c|}
\hline $\begin{array}{l}\text { Spinal accessory nerve motor conduction } \\
\text { study parameters }\end{array}$ & $\begin{array}{l}\text { Patient group (symptomatic } \\
\text { side) }(n=25)\end{array}$ & $\begin{array}{l}\text { Patient group (asymptomatic } \\
\text { side) }(n=25)\end{array}$ & $\begin{array}{l}\text { Control group } \\
(n=20)\end{array}$ & $\begin{array}{l}\text { Test of } \\
\text { significance }\end{array}$ & $P$ \\
\hline \multicolumn{6}{|l|}{ CMAP latency (ms) } \\
\hline Median & 2.50 & 2.40 & 2.15 & $K=13.640$ & $0.001^{*}$ \\
\hline Mean \pm SD & $2.53 \pm 0.37$ & $2.26 \pm 0.28$ & $2.16 \pm 0.25$ & & \\
\hline Min.-Max. & $1.8-3.4$ & $1.6-2.6$ & $1.8-2.7$ & & \\
\hline Test of significance & $Z_{1}=-2.453$ & $Z_{2}=-1.554$ & $Z_{3}=-3.475$ & & \\
\hline$P$ & $P_{1}=0.014^{*}$ & $P_{2}=0.120^{\ddagger}$ & $P_{3}=0.001^{* \S}$ & & \\
\hline \multicolumn{6}{|l|}{ CMAP amplitude (mV) } \\
\hline Median & 12.00 & 14.50 & 12.55 & $K=3.809$ & 0.149 \\
\hline Mean \pm SD & $12.46 \pm 4.95$ & $14.92 \pm 4.84$ & $13.41 \pm 2.89$ & & \\
\hline Min.-Max. & $4.8-24.5$ & $8.0-23.5$ & $9.2-20.2$ & & \\
\hline Test of significance & $Z_{1}=-1.854$ & $Z_{2}=-0.891$ & $Z_{3}=-1.143$ & & \\
\hline$P$ & $P_{1}=0.064^{\dagger}$ & $P_{2}=0.373^{\ddagger}$ & $P_{3}=0.253^{\S}$ & & \\
\hline
\end{tabular}

CMAP compound muscle action potential, $S D$ standard deviation, Min. minimal value, Max. maximal value, $n$ number of subjects, $Z_{1}$ value of Mann-Whitney test for comparing between patient group (symptomatic side) versus patient group (asymptomatic side), $Z_{2}$ value of Mann-Whitney test for comparing between patient group (asymptomatic side) versus control group, $Z_{3}$ value of Mann-Whitney test for comparing between patient group (symptomatic side) versus control group, $K$ value of Kruskal-Wallis test for comparing between the three groups

* Statistically significant at $P<0.05$

${ }^{\dagger} P_{1}$ value for comparing between patient group (symptomatic side) and patient group (asymptomatic side)

${ }^{\ddagger} P_{2}$ value for comparing between patient group (asymptomatic side) and control group

${ }^{5} P_{3}$ value for comparing between patient group (symptomatic side) and control group 


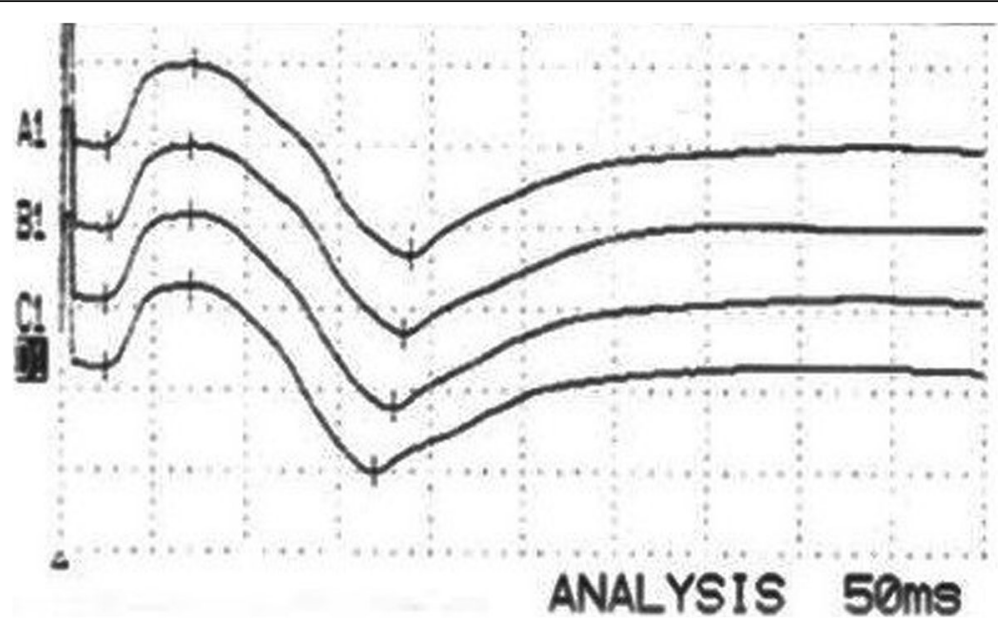

Fig. 2 The spinal accessory nerve (SAN) compound muscle action potentials (CMAP) obtained from an apparently healthy volunteer. The sweep speed was $5 \mathrm{~ms} /$ division and sensitivity was $5 \mathrm{mV} /$ division. SAN CMAP latency was $2.4 \mathrm{~ms}$ and amplitude was $11.7 \mathrm{mV}$

year-old woman-housewife-with right side chronic trapezius MPS of 24 months' duration. Her pain severity assessment using NRS was 10 which increased by repetitive work and excessive loads. She had more than one active MTrPs within the upper segment of the trapezius muscle. Her trapezius muscle on the symptomatic side had subtle wasting of its upper fibers and weakness in the form of grade 4 manual muscle testing using Medical Research Council Scale without winging of the scapula. By electrophysiological examination, there was delayed latency and reduced amplitude of the SAN CMAP on the symptomatic side. The SAN CMAP obtained from the symptomatic and asymptomatic sides of this patient is illustrated in Fig. 3. The needle EMG examination of the trapezius muscle on the symptomatic side revealed abnormalities consistent with chronic axonopathic lesion.

\section{Discussion}

The trapezius muscle is important in maintaining erect posture and contributes in the neck movements. It is a major scapular stabilizer and it contributes to the scapulo-thoracic rhythm [6]. Subsequently, this muscle is always present in sustained contraction [15]. This could contribute to the development of trapezius MPS $[4,5]$. Trapezius muscle is the most common muscle to present with MTrPs. Other shoulder girdle muscles could be affected as infraspinatus and supraspinatus muscles [24-26]. In the present study, the upper segment of the trapezius muscle was the segment that had most of the taut bands and MTrPs in all the participated patients. This indicates that the upper segment is more prone to the development of MPS $[4,5]$.

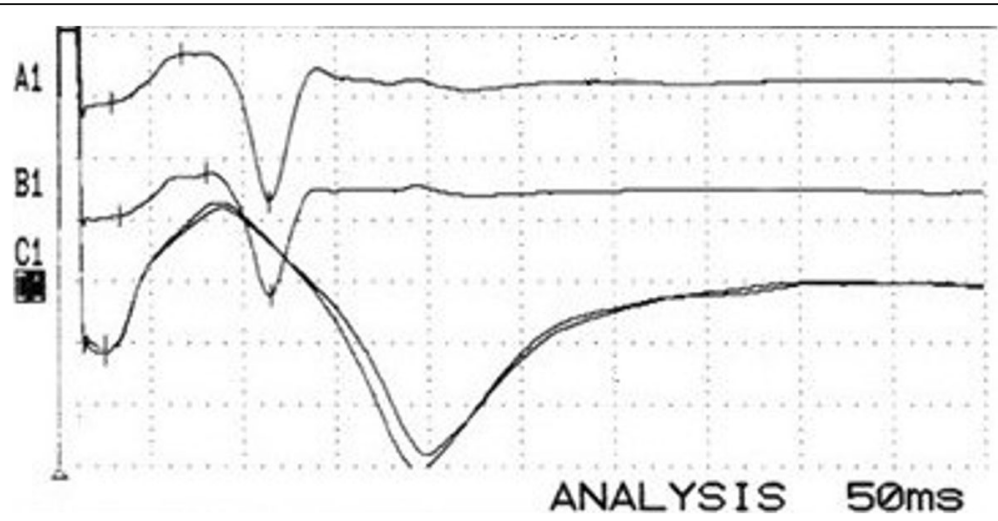

Fig. 3 The spinal accessory nerve (SAN) compound muscle action potentials (CMAP) obtained from the symptomatic (upper two traces) and asymptomatic (lower two traces) sides of a patient with electrophysiological evidence of symptomatic side spinal accessory neuropathy. The CMAP of the upper two traces had delayed latency and reduced amplitude. The sweep speed was $5 \mathrm{~ms} /$ division and sensitivity was $2 \mathrm{mV} /$ division. The upper two traces: SAN CMAP latency was $2.9 \mathrm{~ms}$ and amplitude was $4.8 \mathrm{mV}$. The lower two traces: SAN CMAP latency was $2.6 \mathrm{~ms}$ and amplitude was $8.6 \mathrm{mV}$ 
Table 2 Clinical characteristics of patients with abnormal spinal accessory nerve motor conduction study versus those with normal spinal accessory nerve motor conduction study

\begin{tabular}{|c|c|c|c|c|}
\hline $\begin{array}{l}\text { Clinical } \\
\text { characteristics }\end{array}$ & $\begin{array}{l}\text { Patients with abnormal SAN motor conduction study } \\
\text { ( } n=7 \text { patients) }\end{array}$ & $\begin{array}{l}\text { Patients with normal SAN motor conduction study } \\
\text { ( } n=18 \text { patients) }\end{array}$ & $\begin{array}{l}\text { Test of } \\
\text { significance }\end{array}$ & $P$ \\
\hline \multicolumn{5}{|c|}{ Duration of complaint (months) } \\
\hline Median & 18 & 9.5 & $Z=-1.683$ & 0.097 \\
\hline Mean \pm SD & $20.28 \pm 13.13$ & $12.55 \pm 7.44$ & & \\
\hline Min.-Max. & $10-48$ & $3-24$ & & \\
\hline \multicolumn{5}{|c|}{ Pain severity assessment by NRS } \\
\hline Median & 8 & 6.5 & $Z=-1.803$ & 0.085 \\
\hline Mean \pm SD & $8.14 \pm 2.03$ & $6.61 \pm 1.50$ & & \\
\hline Min.-Max. & $5-10$ & $5-10$ & & \\
\hline \multicolumn{5}{|c|}{ Number of MTrPs } \\
\hline Median & 2 & 2 & $Z=-0.844$ & 0.458 \\
\hline Mean \pm SD & $4.00 \pm 2.82$ & $3.11 \pm 2.51$ & & \\
\hline Min.-Max. & $1-6$ & $1-6$ & & \\
\hline
\end{tabular}

$S D$ standard deviation, Min. minimal value, Max. maximal value, NRS numerical rating scale, MTrPs myofascial trigger points, $S A N$ spinal accessory nerve, $n$ number of subjects, $Z$ value of Mann-Whitney test for comparing between the two groups

*Statistically significant at $P<0.05$

In this study, there was only one patient $(4 \%)$ that had clinical evidence of spinal accessory neuropathy. Electrophysiologically, the SAN CMAP latency was significantly delayed on the symptomatic side in comparison to the contralateral asymptomatic side and control group. This was not applied for the SAN CMAP amplitude. Individually, there were seven patients (28\%) who had electrophysiological evidence of spinal accessory neuropathy. All had evidence of nerve demyelinating lesion while one patient (4\%) had associated axonal degeneration manifested as reduced CMAP amplitude and neuropathic MUAPs in the needle EMG of the symptomatic trapezius muscle.

The diagnosis of spinal accessory neuropathy in patients with chronic trapezius MPS was made by electrophysiological examination in seven patients (28\%). Six patients were clinically free $(24 \%)$ and only one patient (4\%) had subtle wasting and mild weakness of the trapezius muscle.

This study was in agreement with Hefny et al. who reported that the SAN latency was significantly prolonged in patients with chronic neck pain with no difference between patients and control group regarding the SAN CMAP amplitude [14].

The current study was in partial agreement with Chang et al. who mentioned that spinal accessory neuropathy was present in $28 \%$ of their sample of patients with trapezius MPS [15]. They mentioned that spinal accessory neuropathy is an axonopathic lesion manifested by reduced SAN CMAP amplitude with abnormal needle EMG of the trapezius muscle. The difference between this study and the current study could be due to the difference in MPS duration which was longer in the
Chang et al. study. Their disease duration was $2.93 \pm$ 1.37 years [15].

Electrophysiological evidence of SAN demyelination in the form of focal demyelination at the site of nerve entrapment results in delayed latency of the SAN CMAP [22]. In a progressive form, spinal accessory neuropathy could be axonopathic lesion with axonal degeneration. However, the patient in the current study with axonal degeneration had minute clinical manifestations of lower motor neuron lesion as subtle muscle wasting and mild weakness without shoulder winging [6]. This could be because the axonal degeneration occurs in a focal or small fraction of the nerve [15].

It was reported that MPS could result in the development of entrapment neuropathy. There are several examples for MPS resulting in entrapment neuropathies as occipital neuralgia, piriformis syndrome, and meralgia paresthetica [27-29]. This includes spinal accessory neuropathy [12]. MPS could lead to entrapment neuropathy when the peripheral nerve passes through a skeletal muscle with MPS [12]. There are many theories that explain the mechanisms of entrapment neuropathy in association with MPS. Taut bands could lead to muscle shortening with subsequent nerve entrapment. Another theory, entrapment could occur when the nerve passes within the muscle between taut bands or it could be compressed between a taut band and the nearby bone $[12,30-32]$. In the present study, the upper segment of the trapezius muscle had most of the taut bands in all the participated patients. This segment is responsible for posture and certain positions of the neck and shoulder, and these may increase the pressure around the SAN especially during neck spasm [33]. 
The presence of spinal accessory neuropathy in patients with chronic trapezius MPS is due to the entrapment neuropathy of the SAN. The site of SAN entrapment was not within the sternocleidomastoid muscle. The delayed latency indicated that the affection is distal to the site of stimulation of the nerve and proximal to the site of nerve recording [22]. This means that the entrapment takes place within the trapezius muscle due to MPS. This could be due to entrapment of the SAN branches when they cross the taut bands within the muscle [13]. It was found that the MTrPs are located within the trapezius muscle belly and at the entry point of the SAN into the muscle [34].

In the present study, the duration of complaint was longer among patients with spinal accessory neuropathy in comparison to those with normal SAN motor conduction study but without significant difference. There was no significant correlation between the duration of complaint with different SAN CMAP parameters on the symptomatic sides. Increased duration of MPS complaint could be a risk factor for the development of spinal accessory neuropathy.

Patients with spinal accessory neuropathy had more intense pain than those without spinal accessory neuropathy. The presence of spinal accessory neuropathy could contribute to the severity of MPS associated pain by worsening the pain intensity. This was not mentioned in previous studies $[14,15]$. The SAN carries proprioceptive fibers to supply the trapezius muscle. Neuropathy affecting the SAN affects these fibers and this contributes to the neuropathic pain [35]. Nerve entrapment results in neuropathic pain that is described as dull aching pain or burning pain. Entrapment of the SAN affects the nervi nervorum which is the intrinsic innervation of the nerve trunk sheath. It acts as nociceptors. They signal pain from direct stimulation [36, 37]. The spinal accessory neuropathy could be a predisposing factor for nociceptive hypersensitivity of MTrPs and induction of pain [38].

The longer disease duration and more pain severity could give alarm for the possibility of spinal accessory neuropathy in patients with chronic trapezius MPS.

There was no statistically significant difference between patients with spinal accessory neuropathy versus those without spinal accessory neuropathy regarding the number of active MTrPs. So, the number of active MTrPs within the trapezius muscle could not predict the occurrence of spinal accessory neuropathy.

Treatment of MPS could alleviate the spinal accessory neuropathy [29, 39]. Early diagnosis and treatment of trapezius MPS could prevent the progression of a subclinical spinal accessory neuropathy to be severe enough to be clinically obvious [40].
Some limitations were present in the current study. The first limitation was the limited number of participated patients. This could be due to the choice of patients with unilateral chronic trapezius MPS which is more common to be a bilateral problem, as well as the wide variety of exclusion criteria [18]. Further studies on a larger number of patients are recommended for verification of the results of the current study. The second limitation was the limited number of male patients. This is because MPS is more common among females, male patients prefer to seek medical advice in advanced stage of their disease and seek medical advice in their health insurance facilities [18, 41, 42]. The third limitation: needle EMG of the sternocleidomastoid muscle was not performed. This is because none of the patients complained of pain related to sternocleidomastoid muscle, with neither wasting nor weakness and clinical examination revealed absence of evidence of MTrPs in this muscle. The fourth limitation: the current study was obtained in one medical center, so the generalization of the obtained results should be taken with caution.

\section{Conclusions}

In conclusion, spinal accessory neuropathy is common among patients with chronic trapezius MPS. It is a sort of SAN entrapment neuropathy. It could contribute to increased pain severity of MPS. Electrodiagnosis is a good modality for identifying subclinical spinal accessory neuropathy in patients with chronic trapezius MPS.

\section{Abbreviations \\ CMAP: Compound muscle action potential; EMG: Electromyography; NRS: Numerical rating scale; MPS: Myofascial pain syndrome; \\ MTrPs: Myofascial trigger points; SAN: Spinal accessory nerve; SD: Standard deviation}

\section{Acknowledgements \\ The authors are grateful to Prof. Dr. Gihan Abd El-Latif Younis Professor of Physical Medicine, Rheumatology and Rehabilitation, Faculty of Medicine, Alexandria University, Egypt, for her great assistance and continuous support in the revision of the manuscript. \\ The authors are grateful to Mariam Kamal Aziz Saba for her assistance in the statistical analysis. \\ The authors are grateful to Maria Kamal Aziz Saba for her assistance in the preparation of the figures.}

\section{Authors' contributions}

AFEE contributed in the concepts, design, definition of intellectual content, literature search, clinical studies, data acquisition and analysis, manuscript preparation, editing, and revision. She read and approved the manuscript. HAS contributed in the concepts, design, definition of intellectual content, and manuscript revision. He read and approved the manuscript. EKAS contributed in the concepts, design, definition of intellectual content, literature search, clinical studies, data analysis, manuscript preparation, editing, and revision. He read and approved the manuscript.

\section{Funding}

The authors received no specific funding for this work. The authors declare that no financial or material support was provided by any parties and that there are no equity interests, patent rights, or corporate affiliations for this work. This research did not receive any specific grant from funding agencies in the public, commercial, or not-for-profit sectors. 
There were no sponsors or funders (other than the named author) who played any role in study design, data collection and analysis, decision to publish, and preparation of the manuscript.

All research facilities are available in our department with no restrictions.

\section{Availability of data and materials}

The datasets used and/or analyzed during the current study are available from the corresponding author on reasonable request.

\section{Ethics approval and consent to participate}

The local Ethics Committee of Faculty of Medicine, Alexandria University, Egypt (IRB no. 00007555-FWA no. 00015712), approved the study. Date of approval: 31 March 2016

Serial number: 0104437

Written informed consent was given by each.

\section{Consent for publication}

Not applicable.

\section{Competing interests}

The authors declare that they have no competing interests.

\section{Author details}

${ }^{1}$ Physical Medicine, Rheumatology and Rehabilitation Department, Ministry of Health Hospitals, Ministry of Health, Alexandria, Alexandria Governorate, Egypt. ${ }^{2}$ Physical Medicine, Rheumatology and Rehabilitation Department, Faculty of Medicine, Alexandria University, Alexandria, Alexandria Governorate, Egypt.

Received: 22 June 2020 Accepted: 2 July 2020

Published online: 08 December 2020

\section{References}

1. Bennett R (2007) Myofascial pain syndromes and their evaluation. Best Pract Res Clin Rheumatol 21:427-445

2. Meleger AL, Krivickas LS (2007) Neck and back pain: musculoskeletal disorders. Neurol Clin 25:419-438

3. Han SC, Harrison P (1997) Myofascial pain syndrome and trigger-point management. Reg Anesth 22(1):89-101

4. Hong CZ, Hsueh TC (1996) Difference in pain relief after trigger point injections in myofascial pain patients with and without fibromyalgia. Arch Phys Med Rehabil 77(11):1161-1166

5. Ge HY, Nie H, Madeleine P, Danneskiold-Samsoe B, Graven-Nielsen T, Arendt-Nielsen $L$ (2009) Contribution of the local and referred pain from active myofascial trigger points in fibromyalgia syndrome. Pain 147(1-3): $233-240$

6. Wiater JM, Bigliani LU (1999) Spinal accessory nerve injury. Clin Orthop Relat Res 368:5-16

7. Bremner-Smith AT, Unwin AJ, Williams WW (1999) Sensory pathways in the spinal accessory nerve. J Bone Joint Surg (Br) 81:226-228

8. Pu YM, Tang EY, Yang XD (2008) Trapezius muscle innervation from the spinal accessory nerve and branches of the cervical plexus. Int J Oral Maxillofac Surg 37:567-572

9. Tubbs RS, Shoja MM, Loukas M, Lancaster J, Mortazavi MM, Hattab EM et al (2011) (2011) Study of the cervical plexus innervation of the trapezius muscle: laboratory investigation. J Neurosurg Spine 14:626-629

10. Chan PK, Hems TE (2006) Clinical signs of accessory nerve palsy. J Trauma 60:1142-1144

11. Nori S (2016) The spinal accessory nerve injuries. Indian J Dent Res 5:430432

12. Karl HW, Tick H, Sasaki KA (2016) Non-pharmacologic treatment of peripheral nerve entrapment. In: Trescot AM (ed) Peripheral nerve entrapments: clinical diagnosis and management. Springer, Switzerland, pp 27-34

13. Simons DG, Travell JG, Simons LS (1999) Travell and Simons's myofascial pain and dysfunction: The trigger point manual. 2nd edition. Volume 1. Williams and Wilkins, Baltimore

14. Hefny MA, Ghaly MS, Greish SM, Abogresha NM, Ayman E, Fahim AE (2012) Spinal accessory neuropathy in patients with chronic neck pain. World $J$ Rheumatol 2:21-26
15. Chang CW, Chang KY, Chen YR, Kuo PL (2011) Electrophysiologic evidence of spinal accessory neuropathy in patients with cervical myofascial pain syndrome. Arch Phys Med Rehabil 92:935-940

16. Giamberardino MA, Affaitati G, Fabrizio A, Costantini R (2011) Myofascial pain syndromes and their evaluation. Best Pract Res Clin Rheumatol 25:185-198

17. Hawker GA, Mian S, Kendzerska T, French M (2011) Measures of adult pain: Visual Analog Scale for Pain (VAS Pain), Numeric Rating Scale for Pain (NRS Pain), McGill Pain Questionnaire (MPQ), Short-Form McGill Pain Questionnaire (SF-MPQ), Chronic Pain Grade Scale (CPGS), Short Form-36 Bodily Pain Scale (SF-36 BPS), and Measure of Intermittent and Constant Osteoarthritis Pain (ICOAP). Arthritis Care Res 63:S240-S252

18. Bourgaize S, Newton G, Kumbhare D, Srbely J (2018) A comparison of the clinical manifestation and pathophysiology of myofascial pain syndrome and fibromyalgia: implications for differential diagnosis and management. J Can Chiropr Assoc 62(1):26-41

19. Florence JM, Pandya S, King WM, Robison JD, Baty J, Miller JP et al (1992) Interrater reliability of manual muscle testing (Medical Research Council Scale) grades in Duchenne's muscular dystrophy. Phys Ther 72: $115-126$

20. Saba EKA (2016) Electrophysiological study of the ulnar palmar cutaneous nerve in normal individuals. Egypt Rheumatol Rehabil 43:184-189

21. Saba EKA (2017) Electrophysiological study of Martin-Gruber anastomosis in a sample of Egyptians. Egypt Rheumatol Rehabil 44:153-158

22. Preston D, Shapiro B (eds) (2013) Electromyography and neuromuscular disorders: clinical-electrophysiologic correlations. $3^{\text {rd }}$ edition. Elsevier Saunders, Pennsylvania

23. Lew HL, Tsai S (2007) Pictorial guide to muscles and surface anatomy. In: Pease WS, Lew HL, Johnson EW (eds) Practical electromyography, $4^{\text {th }}$ edn. Lippincott Williams \& Wilkins, Philadelphia, pp 145-212

24. Cerezo-Tellez E, Torres-Lacomba M, Mayoral-del Moral O, Sanchez-Sanchez B, Dommerholt J, Gutierrez-Ortega C (2016) Prevalence of myofascial pain syndrome in chronic non-specific neck pain: a population-based crosssectional descriptive study. Pain Med 17:2369-2377

25. Borg-Stein J (2002) Cervical myofascial pain and headache. Curr Pain Headache Rep 6:324-330

26. Ravichandran P, Ponni HK, Aseer PLO (2016) Effectiveness of ischemic compression on trapezius myofacial trigger points in neck pain. Int J Theor Phys 3:186-192

27. Gerwin RD, Dommerholt J, Shah JP (2004) An expansion of Simons' integrated hypothesis of trigger point formation. Curr Pain Headache Rep 8 : 468-475

28. Jankovic D, Peng P, van Zundert A (2013) Brief review: piriformis syndrome: etiology, diagnosis, and management. Can J Anesth 60:1003-1012

29. Gerwin RD (2016) Myofascial trigger point pain syndromes. Semin Neurol 36:469-473

30. Chung T, Prasad K, Lloyd TE (2014) Peripheral neuropathy: clinical and electrophysiological considerations. Neuroimaging Clin N Am 24:49-65

31. Quintner JL, Cohen ML (1994) Referred pain of peripheral nerve origin: an alternative to the "myofascial pain" construct. Clin J Pain 10:243-251

32. Saxena A, Chansoria M, Tomar G, Kumar A (2015) Myofascial pain syndrome: an overview. J Pain Palliat Care Pharmacother 29(1):16-21

33. Novak CB, Mackinnon SE (1998) Nerve injury in repetitive motion disorders. Clin Orthop Relat Res 351:10-20

34. Tough EA, White AR, Richards S, Campbell J (2007) Variability of criteria used to diagnose myofascial trigger point pain syndrome-evidence from a review of the literature. Clin J Pain 23:278-286

35. Restrepo CE, Tubbs RS, Spinner RJ (2015) Expanding what is known of the anatomy of the spinal accessory nerve. Clin Anat 28:467-471

36. Bove GM, Light AR (1997) The nervinervorum: missing link for neuropathic pain. J Pain 6:181-190

37. Teixeira MJ, Almeida DB, Yeng LT (2016) Concept of acute neuropathic pain The role of nervi nervorum in the distinction between acute nociceptive and neuropathic pain. Revista Dor 17:5-10

38. Li LT, Ge HY, Yue SW, Arendt-Nielsen L (2009) Nociceptive and nonnociceptive hypersensitivity at latent myofascial trigger points. Clin J Pain 25:132-137

39. Townsley P, Ravenscroft A, Bedforth N (2011) Ultrasound-guided spinal accessory nerve blockade in the diagnosis and management of trapezius muscle related myofascial pain. Anaesthes 66:386-389

40. Wills AJ, Sawle GV (2010) Accessory nerve palsies. Pract Neurol 10:191-194 
41. Tsang A, Korff MV, Lee S, Alonso J, Karam E, Angermeyer MC et al (2008) Common chronic pain conditions in developed and developing countries: Gender and age differences and comorbidity with depression-anxiety disorders. J Pain 9:883-891

42. Rollman GB, Lautenbacher S (2001) Sex differences in musculoskeletal pain. Clin J Pain 17:20-24

\section{Publisher's Note}

Springer Nature remains neutral with regard to jurisdictional claims in published maps and institutional affiliations.

Submit your manuscript to a SpringerOpen ${ }^{\circ}$ journal and benefit from:

- Convenient online submission

- Rigorous peer review

- Open access: articles freely available online

- High visibility within the field

- Retaining the copyright to your article

Submit your next manuscript at $\boldsymbol{\wedge}$ springeropen.com 